\title{
The Law of Self-Eating-Milk, Placenta, and Feces Consumption
}

\author{
Mathilde Cohen* \\ University of Connecticut, United States
}

\begin{abstract}
Humans have consumed nearly every human body part. Today, the consumption of milk, placenta, and feces, in particular, is on the rise. Milk, placenta, and feces circulate directly among people given that no medical expertise is required to consume them in unprocessed form, but they are also distributed by institutionalized medical entities (e.g., biobanks, hospitals, pharmaceutical, biotechnology, or cosmetic companies). They are considered simultaneously valuable (as they are typically donated gratuitously and primarily used for nutritional, health, and research purposes) and dangerous (as they can transmit viruses, bacteria, parasites, and pollutants). This article has two main goals. First, in examining the social meanings of milk, placenta, and feces consumption, it considers whether and how the circulation of these bio-commodities shapes the limits of human bodies and communities. Second, it asks whether there is something different or specific about the way in which self-consumption (i.e., the consumption of human body materials by humans) is regulated compared to that of foods, drugs, and supplements derived from animal bodies, plants, or other non-human sources.
\end{abstract}

Keywords: Food and drug law, cannibalism, bio-commodity, health law, bio-medical law.

\section{Introduction}

Cora Diamond writes, "[w]e learn what a human being is in - among other ways — sitting at a table where WE [humans] eat THEM [animals]. We are around the table and they are on it." Analogously, this article asks what can be learned about human beings in sitting at a table at which humans eat humans. This article is entitled, "The Law of Self-Eating," but a more fitting title might be, "The Law of Self-Consumption." Instances of humans eating or drinking bodily substances, such as blood, bones, ear wax, fat, hair, milk, mucus, nails, placenta, pus, semen, skin, snot, stool, sweat, tears, teeth, urine, or vaginal fluids, can be found in medico-scientific literature, folklore, historical records, and other sources. ${ }^{2}$ Such substances have been ingested through the mouth and swallowed as a mode of sustenance, medication, enjoyment, or ritual; however, they are not generally considered foods. Indeed, most such substances are regarded as loathsome waste products that should be discarded.

In this article, the word "self" is employed along a continuum. At one end, "self-eating" or "self-consumption" is understood narrowly as eating or consuming one's own body materials. This type of consumption is "autologous," occurring when a person eats their own placenta, drinks their own milk, or engages in autologous fecal transplantation (these are the three body materials analyzed in this paper). At the other end, "self-eating" or "self-consumption" refers to the eating or consumption of another's

\footnotetext{
* Professor of Law, University of Connecticut. For helpful conversations and comments on earlier drafts, I am grateful to Matilda Arvidsson, Daniela Caruso, Athia Choudhury, Maneesha Deckha, Amy DiBona, Elizabeth Emens, Daniel Halberstam, Cressida Limon, Mathieu Morin of the Department of Research in Obstetrics and Gynecology, Toulouse University Hospital, France, Yoriko Otomo, Kim Lane Scheppele, and to an anonymous journal referee. I also thank the participants of the "Eggs, Milk and Honey: Law and Global Biocommodities" workshop, which was held at Western Sydney University in September of 2018, and as well as the participants of the European Union Law Scholarship Roundtable held at Columbia Law School in November of 2018 for their feedback. Finally, I thank Megan Grant for her research assistance as well as the University of Connecticut law library staff, in particular Tanya Johnson, Adam Mackie, and Anne Rajotte, for their library assistance.

${ }^{1}$ Diamond, "Eating Meat and Eating People," 470.

${ }^{2}$ Schutt, Cannibalism.
} 
human body. This type of consumption is "allogeneic," occurring when someone eats another person's placenta, drinks their milk, or obtains their feces to perform a fecal transplantation. In between these two poles, the "self" may also denote kin or other relations between the eater and the eaten, the consumer and the consumed. Such individuals may belong to the same family; for example, a partner who eats their companion's placenta, a child who is breastfed by their parent, or a relative who receives a donation of feces. Such individuals may also be friends or acquaintances; for example, a birth team member who prepares and tastes another person's placenta or milk, or a neighbor who donates their stool. Finally, even when individuals are unrelated by blood, family, or social ties, the eaters and the eaten, and the consumers and the consumed tend to belong to similar groups, particularly in terms of class, race, and ethnicity.

The idea of "consumption" is broader than that of eating, which refers to swallowing by the mouth and digesting. Humans can incorporate others' body parts into their bodies in a variety of ways that extend beyond the sole act of eating but still fall within the notion of consumption. For example, someone else's fecal matter can be assimilated via a colonoscopy, nasal tubes, or an enema, salves and lotions comprising ingredients such as milk, skin, or placenta can be applied, capsules or pills filled with bodily matter, such as fecal suspension, freeze-dried fecal preparations, or dried placenta can be ingested, blood can be transfused and organs can be transplanted. Additionally, the notion of consumption may refer to the purchase of goods or services. It not only denotes incorporation and absorption into the body, but also the potential subjection to market forces that are at work in contemporary milk, placenta, and feces consumption. ${ }^{3}$ This economic dimension is crucial given the tensions between peer-to-peer markets (which are sometimes framed as alternatives to conventional markets, in part because in many instances money does not change hands) and established medical, food, drug, and cosmetic markets.

Milk, placenta, and feces are circulated among people both via peer-to-peer interactions and via organizations, such as biobanks, hospitals, and biotechnology, cosmetic, and pharmaceutical companies. Such substances are considered both valuable (as they can be used for nutritional, health, and research purposes) and dangerous (as they can transmit viruses, bacteria, parasites, and pollutants). No medical expertise is necessary to retrieve milk, placenta, and feces or to consume them in their unprocessed form. This do-it-yourself (DIY) potential is empowering for individuals who may be motivated to engage in peer-to-peer markets as a critique of mainstream forms of consumption and due to a distrust of the medical industrial complex. This selfhelp dimension is key for those who cannot access these bio-commodities via more conventional channels either because they are too expensive or because medical professionals will not dispense them for their particular indication. Thus, people can "take back" their own body parts by becoming entrepreneurs of themselves and organizing markets that enable personalized exchange relations. ${ }^{4}$ However, public health professionals, healthcare providers, and regulators may be concerned about the health risks involved in direct-to-consumer body markets and the loss of control and revenue that these markets represent.

This article has two main goals. First, in examining the social meanings of milk, placenta, and feces consumption, it considers whether and how the circulation of these bio-commodities shapes the limits of human bodies and communities. Second, it asks whether there is something different or specific about the way in which self-consumption is regulated compared to that of foods, drugs, and supplements derived from animal bodies, plants, or other non-human sources.

This article builds upon the growing critical feminist scholarship in sociology, law, and anthropology on bio-commodities, extending its findings to lesser known materials, such as placentas and feces. Legal and feminist cultural analyses of human milk are booming; however, such analyses are less common in relation to placenta, and practically non-existent in relation to feces. ${ }^{5}$ Charlotte Kroløkke, a pioneer in this field, studies women's reproductive donations of urine, eggs, and placentas and argues that these are "global fluids" in the sense that "they have become liquid and globalized, along with cultural values, laws, exchange systems, and ethics." Building on Kroløkke's work, this article examines often neglected bio-commodities from the novel perspective of self-consumption. However, it should be noted that it does not engage with the literature on the commodification of the body and its parts; rather, commodification is taken as a given that is neutral in and of itself and this article focuses on the ways in which individuals retain ownership over and access their own or others' milk, placenta, and feces.

Part I outlines the various ways in which humans consume milk, placenta, and feces. Part II considers the social meanings associated with these consumption practices, arguing that they contribute to defining participants' identities as individuals and members of communities. Finally, Part III examines the role of the law in either facilitating or hindering access to the consumption of milk, placenta, and feces, especially in the context of the United States (U.S.) legal system.

\footnotetext{
${ }^{3}$ Cohen, "The Law of Placenta"; Cohen, "Should Human Milk Be Regulated?”; Kroløkke, Global Fluids; Sachs and Edelstein, "Regulation of Fecal Microbiota."

${ }^{4}$ Rose, Powers of Freedom, 230.

${ }^{5}$ But see Donley, "Regulation of Encapsulated Placenta."

${ }^{6}$ Kroløkke, Global Fluids, 2.
} 


\section{Part I: Consuming Milk, Placenta, and Feces}

\section{A-Humans Eat Humans}

Nearly every human body part has been consumed by humans, including amniotic fluid, blood, bones, cartilage, ear wax, fat, hair, marrow, milk, mucus, nails, placenta, pus, saliva, semen, skin, snot, stool, sweat, tears, teeth, urine, and vaginal fluids. Typically, this consumption is part of a medicinal practice - one person consumes body materials drawn from another person to cure an ailment. The use of blood as therapy has been documented since at least the first century C.E. when Pliny reported that drinking blood was a cure for epilepsy. ${ }^{7}$ English physicians still recommended that blood be used to treat epilepsy as late as $1747 .{ }^{8}$ There is a long European history, particularly in the seventeenth and eighteenth centuries, of what anthropologists refer to as medical cannibalism; that is, the use of a variety of human tissue, which was often obtained from executed criminals or at mummy shops, for therapeutic purposes. ${ }^{9}$ This practice was not confined to Europe. For centuries, China has known a "publicly and cultural sanctioned" "practice of consuming certain . . . parts of the human body." 10 These traditions continue today in mainstream medicine. Blood transfusion and organ transplantation are routine standards of care. It has been said that the future of medicine lies in cell therapy (i.e., the use of human cells to cure human cells) and microbiome therapy (i.e., the use of microbial communities from other humans, animals, or the environment to rebalance a patient's microbiome). ${ }^{11}$

The human body is sometimes viewed as dualistic; it is seen simultaneously as an object of medical care and as a source of medicine. However, rather than being a cure, the act of eating parts of the human body may also be considered an illness. Examples include the "Rapunzel syndrome" (the ingesting of one's hair), "dermatophagia" (the eating of one's nails and skin), or more generally, "self-cannibalism" (the eating of one's own body parts, such as flesh or organs)..$^{12}$ Humans' consumption of their own or others' bodies is not confined to the medical realm. In some instances, body consumption is nutritional, cosmetic, spiritual, or recreational. For example, human milk has been touted as a post-workout recovery nutritional drink, a new wondermoisturizer cosmetic beauty treatment, a vector for kinship, and an ingredient in experimental cuisine or art performances. ${ }^{13}$ In sum, humans eating humans is alternatively considered normal or deviant depending on the circumstances and the body materials involved.

\section{B-Milk, Placenta, and Feces}

\section{1-Milk}

Since antiquity at least, there have been markets in human milk. Until the twentieth century, they relied primarily on wet nurses hired (or forced) to nurse infants directly on the breast. ${ }^{14}$ Ancient Egyptian, Greek, and Roman pharmacopeias called for human milk as a therapeutic substance to treat burns as well as ailments affecting the ears, eyes, and genitals. ${ }^{15}$ Traditional Chinese medicine employed human milk in a variety of preparations to cure diseases, such as debilitation, arthritis, rheumatism, voicelessness, amenorrhea, eye infections, and poisoning. ${ }^{16}$

Today, markets in human milk continue to thrive. ${ }^{17}$ Such markets assume two main forms: 1 ) informal markets through which people give or sell their milk peer-to-peer via their social circles or online; and 2) formal markets whereby profit or non-profit organizations, such as milk banks and commercial human milk companies, collect, process, and distribute milk to hospitals and a few outpatients for a fee. Human milk is sought after by three main categories of consumers: infants, adults, and researchers. The need for donor milk for babies arises when parents cannot lactate themselves or lactate insufficiently to meet the needs of their babies. The primary infant population that requires donor human milk comprises severely sick infants and premature and low weight babies whose odds of healthy survival have been shown to increase when they are fed additional donor milk instead of formula. ${ }^{18}$ There are also adult uses for human milk; for example, some cancer patients believe that milk can hasten their recovery and minimize the side effects of certain drugs. ${ }^{19}$

\footnotetext{
${ }^{7}$ Lindenbaum, "Thinking about Cannibalism," 478.

${ }^{8}$ Gordon-Grube, "Anthropophagy in Post-Renaissance Europe" 407.

${ }^{9}$ Lindenbaum, "Thinking about Cannibalism," 478.

${ }^{10}$ Chong, Cannibalism in China, 2.

${ }^{11}$ Hoffmann, "Introduction."

12 Ahuja and Lloyd, "Self-Cannibalism."

${ }^{13}$ Cohen, "Should Human Milk be Regulated?"

${ }^{14}$ Fildes, Wet Nursing.

${ }^{15}$ Laskaris, "Nursing Mothers."

${ }^{16}$ Cooper, "Man as a Medicine," 227-234.

${ }^{17}$ Palmquist, "Contextualizing Online Human Milk Sharing Practices."

${ }^{18}$ American Academy of Pediatrics Section on Breastfeeding. "Breastfeeding and the Use of Human Milk."

${ }^{19}$ Major, "Fighting Cancer."
} 
Finally, human milk is used for both public and private research. Some of this research pertains to maternal and infant health. Other research focuses on the specific components of human milk, which scientists are seeking to isolate so that they can eventually be used in infant formula or laboratory developed drugs for the general public. In the past decade, research has shown that human milk contains stem cells with multilineage potential (i.e., cells that can renew tissue in the body). ${ }^{20}$ It is thought that such stem cells could be used in the future to create transplantable tissue and treat presently incurable conditions, such as Parkinson's disease, Alzheimer's disease, and strokes. Researchers are also currently investigating whether human milk antibodies from people who have recovered from COVID-19 could be used to treat others. ${ }^{21}$

\title{
2-Placenta
}

Human placentas are used for spiritual, nutritional, medical, pharmaceutical, and cosmetic purposes. Placentophagy, or the act of eating one's placenta after childbirth, has been practiced in the Global North since the beginning of the home- and naturalbirth movement in the 1970s. ${ }^{22}$ It is not an unprecedented phenomenon. Indeed, historian Jacques Gélis reported that:

\begin{abstract}
Placentophagy, the custom of eating the newly expelled placenta, has existed at various times amongst people of very different cultures. From the sixteenth century onwards, European travellers to the new world were much struck by this custom, which they unfailingly reported. ${ }^{23}$
\end{abstract}

According to Gélis, placentophagy was also practiced in Europe; however, "doctors and churchmen were more and more repelled, from the end of the seventeenth century onwards, by this custom . . . so "repugnant to humanity." 24 In the past decade, placentophagy has reemerged as a mainstream practice in the U.S., where it has been described as "a new American birth ritual. ${ }^{25}$

Few randomized controlled trials have corroborated the benefits of placentophagy. However, placenta eaters are motivated by the hope of obtaining nourishment, hastening post-birth recovery, warding off postpartum depression, facilitating lactation, as well as spiritual motives, such as connecting with the baby and the environment. Placentas can be eaten raw or cooked. They can also be processed for use in lotions, salves, and tinctures, encapsulated in pills, and used to produce artefacts, such as prints and keepsakes. It is primarily individuals who identify as women who consume their own placentas; however, their partners, children, friends, and relatives may also partake in the consumption of placentas.

Markets in placentas exist beyond the family and friendship circles. These markets are mediated by cosmetic, medical, and scientific entities. In the U.S., various companies bank placentas for personal or family use for a fee with the promise that stem cells for future therapeutic use can be obtained from the cord blood, the placenta, and its membranes. ${ }^{26}$ Placentas can also be donated to research institutions, the pharmaceutical industry, biotech companies or, more rarely, directly to the public. As Rebecca Yoshizawa notes:

$$
\begin{aligned}
& \text {... beyond reproductive biology, placentas and associated tissues are employed in diverse fields such as immunology, stem cell } \\
& \text { research, environmental sciences and toxicology, genetics, hypertension research, cancer research, and tissue engineering, and } \\
& \text { they have many therapeutic applications. }{ }^{27}
\end{aligned}
$$

Charlotte Kroløkke and her colleagues have shown that placentas are also used "as a commercial extract and vital ingredient in anti-ageing and whitening creams produced by the cosmetics industry." 28

Minimally processed placental membranes have significant commercial and medical potential to treat, among other indications, eye diseases and acute and chronic wounds. The for-profit American company MiMedx also "grinds up amniotic tissue from placenta into an injectable product to treat tendinitis, strains, and other ailments." ${ }^{29}$ Much like human milk, placentas are increasingly seen as reservoirs of stem cells and thus are attractive to the field of regenerative and tissue engineering, and, more recently, as potential sources for treating coronavirus patients. ${ }^{30}$ Placenta stem cells are easily obtainable, as they do not require

\footnotetext{
${ }^{20}$ Hassiotou, "Breastmilk is a Novel Source of Stem Cells."

${ }^{21}$ Fox, "Evidence of a Significant Secretory-IgA-dominant SARS-CoV-2 Immune Response."

22 Hayes, "Consumption of the Placenta," 79.

${ }^{23}$ Gélis, History of Childbirth, 170.

${ }^{24}$ Gélis, History of Childbirth, 170.

25 Janszen, "Meat of Life," 78.

26 Pipino, "Placenta as a Reservoir of Stem Cells."

27 Yoshizawa, "Review: Public Perspectives," 9.

${ }^{28}$ Kroløkke, "The Placenta Economy," 142.

${ }^{29}$ Germano, "Placenta-Products Maker MiMedx Draws FDA Attention."

30 Jeffay, "Israeli Firm Hopeful."
} 
invasive collection procedures and "offer advantages in terms of proliferation and plasticity." 31 Often, it is difficult for patients to easily find matched donors for stem cells from traditional sources, such as embryos. Consequently, it has been proposed that stem cells be harvested from placentas to increase the number of stem cells available.

3-Feces

Excrement is typically regarded as disgusting; however, the medical use of human and animal feces has a long record. Heinrich von Staden notes that:

\begin{abstract}
Most prominent among the ingredients in the Hippocratic pharmacological 'dirt' arsenal is the excrement of various animals. . . . the belief in the therapeutic usefulness of excrement was shared by ancient Mesopotamian, Egyptian, Greek, Chinese Talmudic, and Indian healers. . . There is, therefore, abundant evidence that . . 'excrement therapy' — was a cross-cultural phenomenon extant already in the ancient world. ${ }^{32}$
\end{abstract}

In Chinese medicine, human feces were used 1,700 years ago as a "suspension by mouth for patients who had food poisoning or severe diarrhea." 33

Fast forward to the twentieth century, the community of microorganisms that dwell in the human gut has been shown to play a crucial role in human health. Fecal microbiota transplantation ("FMT") was first identified in the modern scientific literature in $1958^{34}$ and has rapidly grown in popularity since the early 2010s. FMT consists in the delivery of processed stool from a healthy donor into the intestinal tract of a sick person via an enema, colonoscopy, naso-duodenal tube, capsules, or other means. As microbiologist Mark Smith and his colleagues noted, "[t]he goal is to displace pathogenic microbes from the intestine by re-establishing a healthy microbial community." ${ }^{35}$ FMT has proven strikingly effective in treating Clostridium difficile, a potentially lethal infection that most commonly affects older adults in hospitals or in long-term care facilities, typically after the use of antibiotics. Research on the effects of FMT is also being conducted in relation to other indications, such as inflammatory bowel disease, obesity, and conditions linked to gut microbiome composition, such as asthma, cancer, food allergies, neurodegenerative and neurodevelopmental disorders. ${ }^{36}$ The results of a 2018 randomized clinical trial suggests that autologous FMT (i.e., the transplantation of a patient's own feces into themselves) could be extremely beneficial in certain circumstances, such as when a patient has completed a round of antibiotics that kills beneficial bacteria. ${ }^{37}$ At the time of writing, the scientific community is grappling with the COVID-19 crisis and the findings that FMT may transmit the virus but may also serve as rescue therapy for critically ill patients.

People seeking to consume feces medicinally can obtain it either from peer-to-peer markets, the few established stool banks, or physicians. Stool banks - the name of which sounds oxymoronic, but also epitomizes the changing valence of bodily substances from dirt to gold — collect feces from screened donors, process it, and distribute it to patients for limited indications only. DIY fecal transplants are on the rise. Indeed, "[r] oughly 4,260 videos concerning 'fecal transplant' can be found [on] YouTube . . . many [of which are] styled as 'how-to' guides." 38 Peer-to-peer markets function in a manner similar to that of peer-to-peer milk markets. Consumers who cannot obtain FMT through their doctors seek donors among their family, circle of friends, or strangers they meet online, and perform the transplant at home.

\title{
4-Why these three?
}

Milk, placenta, and feces differ in important ways. First, human milk is the only one of the three substances that is universally considered a food and that is actually consumed by the vast majority of humans in infancy. Second, milk, placenta, and feces diverge in terms of their consumer bases. Drinking one's own milk and consuming one's own feces are viewed as oddities (auto-coprophagy in particular is considered a symptom of mental illness even though autologous fecal transplants appear to effectively restore gut microbiota diversity). Conversely, the eating of one's own placenta or consuming it in other ways is becoming mainstream. However, these are differences in degree rather than nature, as the three materials can and have been consumed by those who produce them and by others. Third, the placenta and milk economies are gendered in a way that FMT is not. Milk and placenta are derived from reproductive labor. Their availability typically requires that a person be pregnant, deliver a baby, and initiate lactation postpartum. The consumption of milk and placentas reflects an extreme form of

\footnotetext{
${ }^{31}$ Pipino, "Placenta as a Reservoir of Stem Cells," 60.

${ }^{32}$ von Staden, "Women and Dirt," 7-8.

${ }^{33}$ Zhang, "Should We Standardize the 1,700-year-old Fecal Microbiota Transplantation?," 1755.

${ }^{34}$ Eiseman, "Fecal Enemas an Adjunct."

${ }^{35}$ Smith, "Policy: How to Regulate Faecal Transplants," 290.

${ }^{36}$ Borody, "Fecal Microbiota Transplantation."

${ }^{37}$ Taur, "Reconstitution of the Gut Microbiota."

${ }^{38}$ Flanagan, "People are Attempting DIY Fecal Transplants."
} 
"reproductive consumption," 39 as it is not only contraceptive, reproductive and diagnostic technologies, and birthing choices that are being consumed, but also the products of reproduction itself. By contrast, regardless of sex, gender, or reproductive status, everyone carries microbiota and everybody defecates. Thus, anyone could donate, sell, receive, or buy fecal matter. However, it should be noted there may be gendered and reproductive aspects to FMT. Some studies have shown that the human microbiome can be maternally transmitted (i.e., that infants acquire microbial strains from their gestational parents' bodies, through vaginal delivery and breastfeeding in particular). ${ }^{40}$ Thus, human microbiomes can be thought of as another product of reproductive labor, at least initially. Additionally, feces consumption used to be gendered and may still be in some respects. In antiquity, Hippocratic doctors prescribed (animal) feces nearly exclusively to female patients and always to cure some type of shameful womanly impurity, such as infertility, abnormal vaginal discharges, or the aftereffects of a miscarriage. According to von Staden, such uses reflect the "frequent assimilation of a uniquely or distinctively female activity to 'dirt', and especially, of linking uterus-related matters with excretory pollution." 41

Despite these differences, milk, placenta, and feces share two sets of core similarities that justify their grouping in this analysis. First, milk, placenta, and feces are tissues that can be severed from the body without harm or risk of harm. Notably, milk and feces are replenishable bodily substances, while the placenta is a transient organ expelled from the body during childbirth. Thus, far from constituting "corpse medicine"42 (i.e., medicine that uses human materials obtained from dead bodies), the use of such substances can be characterized as living food or medicine. There are also no adverse health effects associated with the act of donation. Quite the opposite, good health requires that people eject the milk, placenta, and feces they produce from their bodies. These substances are also living in the sense that they are dynamic. Their immunological, hormonal, nutritional, microbial, and metabolic contents vary across individuals and over time within individuals. However, as composition cannot be guaranteed from batch to batch, it is extremely difficult to define the active ingredients required for therapeutic uses.

Second, these three products have similar channels of circulation, including via private, domestic consumption, peer-to-peer markets, medical and research institutions, and global markets in foods, drugs, and cosmetics. This wide scope for circulation is possible due to the potential for DIY treatments alongside higher tech uses involving special processing and expertise. Milk, placenta, and feces are collected, processed, and distributed by banks similar to other tissue banks; however, aspiring consumers can also obtain milk, placenta, and feces and use them on their own. Unlike blood transfusion or organ transplantation, no professional expertise or complicated equipment is necessary to achieve basic forms of consumption. Milk, placenta, and feces can be obtained directly from their producers after some screening (or not) and consumed as is or minimally processed at home. Conversely, bio-banks systematically screen donors, subjecting them and their samples to a battery of tests, before processing their products in various ways; for example, by freezing, thawing, pooling, enriching, freeze-drying (in the case of milk), irradiating (in the case of placenta), encapsulating (in the case of stool). This is a fast-evolving field. It could be that future research will transform the way in which milk, placenta, and feces are used. Should their beneficial active ingredients be identified and isolated, new forms of consumption could be devised in the form of laboratory produced drugs. This development may deepen the split between the medical-industrial uses of milk, placenta, and feces in medicalized products and the directto-consumer model, under which the materials are barely altered.

\section{Part II: Human Bodies, Human Communities}

\section{A-The Limits of Human Bodies}

By questioning what goes in and out of human bodies, the consumption of milk, placenta, and feces breaks down the dualism between the inside and the outside of human bodies. Julia Kristeva once famously claimed that the fact that a substance is expelled from inside the body makes it abject. ${ }^{43}$ The abject threatens people's perceptions of their bodies as "clean and proper" and distinct from organic matter that rots away. In the context of lactation in particular, Fiona Giles noted that there is a "taboo against performing a bodily function in public, except for eating. It's okay to see things going into our bodies but not to see anything coming out. Even tears can cause social consternation." ${ }^{44}$ However, a distinctive feature of milk, placenta, and feces is that in addition to coming out of the body, they can also make it back in, blurring the line between waste and body, food and body, medicine and body, and ultimately, one body and another body.

\footnotetext{
${ }^{39}$ Fletcher, "Reproductive Consumption."

40 Asnicar, "Studying Vertical Microbiome."

${ }^{41}$ von Staden, "Women and Dirt," 14. It could be that persisting gender hierarchies perpetuate the negative linkage between women and feces and thus inform who gets to participate in FMT and peer-to-peer feces markets. One study suggests that women are less likely than men to donate their feces, as they find "donating feces unappealing": Jørgensen, "Recruitment of Feces Donors," 542.

${ }^{42}$ Sugg, "Good Physic but Bad Food," 225.

${ }^{43}$ Kristeva, Powers of Horror, 2-3.

${ }^{44}$ Giles, "Two Breasts, Twelve Weeks," 106-7.
} 
Milk and placenta, in particular, are relational substances in the sense that they are produced by one body for another body. According to Cressida Heyes, the placenta:

... challenges an ontology of separability ... it undermines the boundedness of the embodied individual. The body of the mother/fetus is neither self-evidently one nor two and the placenta is the liminal organ through which that mutual incorporation is most apparent. ${ }^{45}$

Pablo Santoro theorizes that the placenta is liminal tissue "whose function is to connect, to mediate, embody contending versions of the political and societal bond," 46 linking children with communities, rooting them in particular places as shown in the tradition of burying the placenta near the home or in some cultures, underneath a tree. Similarly, milk is an interdependent fluid. Breastfeeders literally transform their food intake and parts of themselves to excrete milk, but their lactation is typically triggered and maintained by the suckling of a child. The composition of milk is also reactive to the needs of particular nurslings, such that different antibodies, nutrients, and hormones are delivered in response to what a specific child needs at any given moment. ${ }^{47}$ Placenta and milk are thus co-produced by two people (or more, in the case of multiple births). To some extent, feces can also be understood as a relational substance, as the microbiome is initially transmitted by the birthing parent.

\section{B-The Limits of Human Communities}

There is something seemingly new about today's bio-economy in that it involves a dimension of stranger sharing. ${ }^{48}$ Koen Frenken and Juliet Schor note that:

Historically, although there are exceptions, people tended not to share with strangers or those outside their social networks. Sharing was confined to trusted individuals such as family, friends and neighbours. Today's sharing platforms facilitate sharing among people who do not know each other, and who lack friends or connections in common. ${ }^{49}$

This is true of milk, placenta, and feces, which consumers may now obtain from strangers whom they have met online or from anonymous donors via the medical, pharmaceutical, or cosmetic industries. However, peer-to-peer markets still perpetuate intimate forms of sharing or at least sharing along communitarian lines. In a study of milk sharing practices in the U.S., Aunchalee Palmquist and Kristie Doehler found that most "recipients reported sharing milk with some combination of family members $(11.1 \%, 2 / 18)$, friends $(61.1 \%, 11 / 18)$, a donor whom they met in their local community $(50.0 \%, 9 / 18)$, and online acquaintances $(61.1 \%, 11 / 18) . "{ }^{50}$ When milk was obtained from people encountered online, it was "generally . . . delivered face-to-face," " signaling not only the desire to create a relationship between the donor and the recipient, but also the geographic proximity, and thus perhaps the social proximity between donors and recipients. Similarly, cases of placenta eating by people other than the placenta producer herself are generally reported as occurring within a family unit or circle of friends. As for feces, "[historically], the majority of FMT donors have been a spouse, relative, or close friend (patient-identified donors)." 52

Depending on the intended use for milk, placenta, and feces, there may be physiological reasons why body materials are kept within kin or close acquaintances. These substances are fungible and can thus theoretically be consumed by anyone regardless of blood type or tissue compatibility, but growing scientific evidence suggests that some donor-recipient matching may be beneficial, particularly for milk and feces. ${ }^{53}$ Breastfeeders produce milk that is responsive not only to their children's nutritional and immunological needs, but also to the surrounding environment; indicating that consuming milk from a donor living in the same milieu and producing milk for a child of a similar age and needs could be beneficial to the recipient. Comparably, patientidentified fecal microbiota donors may have the advantage of sharing the greatest number of microbial species with the recipient if they live in proximity to one another and share lifestyle elements and exposure to germs and bacteria. ${ }^{54}$

Further, the social and relational contexts of sharing, rather than simply the anticipated benefits of milk, placenta, and feces consumption, may explain donors' and recipients' forms of engagement with these markets. The circulation of these substances generates forms of cooperation and imagined communities in ways that are comparable to the circulations of other goods. Juliet

\footnotetext{
${ }^{45}$ Heyes, "Placenta-Eating," 113.

${ }^{46}$ Santoro, "Liminal Biopolitics," 77.

${ }^{47}$ Hinde "Mother's Littlest Helpers," 1427.

${ }^{48}$ Schor, "Collaborating and Connecting," 415-6.

49 Frenken, "Putting the Sharing Economy into Perspective," 4.

${ }^{50}$ Palmquist, "Human Milk Sharing Practices," 283.

${ }^{51}$ Palmquist, "Human Milk Sharing Practices," 280.

${ }^{52}$ Lee, "Fecal Microbiota Transplantation," 26.

${ }^{53}$ Wilson, "The Super-Donor," 3 (Fig. 1).

${ }^{54}$ Bakken, "Treating Clostridium Difficile."
} 
Schor and Connor Fitzmaurice argue that "[s]haring among kin and community ensures that exchange partners have a basis for trust based on pre-existing social relationships. But it also ensures the types of informal social controls needed to generate impersonal trust." 55 Thus, milk, placenta, and feces consumption appear tied to particular demographics defined along socioeconomic and racial lines. Palmquist and Doehler note that "milk sharing appears to be commonplace in the U.S., notably among middle-income, college educated women who self-identify as Caucasian/white." 56 Despite a lack of in-depth research on the profiles of FMT donors and users, initial reports suggest a striking racial difference among patients treated for Clostridium difficile (C. difficile) infection. Specifically, a 2016 study reported that $C$. difficile is more prevalent among white Americans than Black Americans and that Blacks treated for the infection experience more severe infections and a higher mortality rate. ${ }^{57}$ The differences in $C$. difficile rates may be related to anti-Black racism and discrimination in medical treatment in addition to disparities in health care coverage and access. In the U.S., whites tend to have greater access than other groups to healthcare and antibiotics; however, together with increased healthcare setting interactions, cumulative exposure to antibiotics is the greatest risk factor for infection. White Americans thus contract more cases of $C$. difficile and are treated at higher rates than other groups. ${ }^{58}$ Conversely, the fact that Black Americans tend to have less access to healthcare and antibiotics has had a protective effect on $C$. difficile; however, when Blacks contract the disease, they are less likely to be correctly diagnosed and receive appropriate care. This raises the question of whether Black Americans are less likely to donate or receive fecal microbiota. Data is lacking here. A study examining attitudes toward FMT for treating $C$. difficile found that those with "presumably greater health literacy," (i.e., "with college degrees or higher"), "were more likely to agree to FMT," but no difference was noted based on race, ethnicity, or income. ${ }^{59}$

In sum, exclusion and sociodemographic factors appear to play a role in access to and attitudes toward milk, placenta, and feces consumption. Alternative treatments, such as human milk feeding, placentophagy, and fecal transplantation, are typically accompanied by increased out-of-pocket expenses that are not covered by health insurance and thus may be prohibitive for many ${ }^{60}$ Overall, more privileged members of society have access to milk, placenta, and feces, be it through the conventional healthcare system or peer-to-peer markets.

The racial and socioeconomic disparities found in peer-to-peer markets suggest yet another story-that participants discriminate, reproducing their communities' boundaries in deciding who to give, sell, buy, or receive products from. Despite a rhetoric of cooperation and mutuality opposed to the global corporate economy and medical monopoly, body materials may increase health and other inequalities. ${ }^{61}$ People use the consumption of bodily materials to express their identity as individuals and group members just as they do other goods. Consuming milk, placenta, and feces — and consuming them in a certain wayplaces a consumer in a particular social group. The parents who eat their placenta as a stew and the parents who pay a private tissue bank to store their placenta may be divided by differences in economic means and opinions along cultural, ideological, and other lines that need to be taken into account when considering the regulation of such products.

\section{Part III: The Law of Self-Consumption}

\section{A-The Co-Creation of Law and Self-Consumption}

No uniform perspective has emerged on the legal classification of the various body materials consumed by humans. In this respect, milk, placenta, and feces provide a case in point, as they do not fit neatly within the standard legal classifications for comparable products, such as foods, drugs, tissues, cosmetic ingredients, or waste products. Different countries have adopted contrasting legal regimes — or no regimes at all — to regulate these substances. As Alexandra Scheeler showed in her analysis of the regulation of fecal transplantation in 55 countries, legal approaches tend to fall into one of four categories. Ranging from the most to the least restrictive, feces may be used in: 1) biologic drugs and subject to strict regulations and restricted uses; 2) human-cell and tissue-based products and subject to process-focused regulations; 3) medicinal products, which often have a temporary status involving varied conditions; and 4) the practice of medicine, which relies on delegating oversight to medical professionals. ${ }^{62}$ In spite of their diversity, these regulatory approaches raise two central questions: 1) Is there something different or specific about the way in which self-consumption is regulated as opposed to the regulation of foods, drugs, and

\footnotetext{
55 Schor, "Collaborating and Connecting," 417.

56 Palmquist, "Human Milk Sharing Practices," 278.

${ }^{57}$ Argamany, "Clostridium Difficile Infection Health Disparities."

${ }^{58}$ Mao, "Racial Differences in Clostridium Difficile."

${ }^{59}$ Park, "Perceptions of Fecal Microbiota Transplantation," 83 and 86.

${ }^{60}$ Young, "Of Poops and Parasites," 557.

${ }^{61}$ Schor, "Collaborating and Connecting, "414-415. In some respects, this hypothesis echoes anthropologists' distinction between "endo-" and "exo-cannibalism."

62 Scheeler, "Where Stool is a Drug," 527.
} 
supplements derived from animal bodies, plants, or other non-human sources; and 2) If so, does the law treat instances in which people consume their own bodies (i.e., autologous uses) differently to instances in which they consume other people's bodies (i.e., allogeneic uses)?

Self-consumption has a long history of instrumentalization by lawmakers under the provocative label of "cannibalism," which has been exploited to justify legal interventions. As Katherine Biber and Mike Hayes have argued, during the modern era, the real or imaginary practice of anthropophagy represented an essential site for white Europeans to justify colonialism and enact laws that supported imperial projects. ${ }^{63}$ In the context of Australian colonialism, it is particularly evident that "law and cannibalism produce each other." ${ }^{44}$ Indigenous Australians were depicted as flesh eating natives as a means to rationalize their subordination and oppression; however, it was actually the white colonists who ate one another. ${ }^{65}$ Brian Simpson's scholarship on British and American legal history shows that cannibalism was in fact closely associated with the European colonial invasion. ${ }^{66}$ Starting in the seventeenth century, a custom of the seas legitimized the practice of white seamen, who were traveling between metropoles and colonies and who survived shipwrecks, killing and eating their weakest passengers. This maritime cannibalism was instrumental in the development of the common law, prompting the creation of the legal doctrine of necessity. ${ }^{67}$ In the U.S. the defense of necessity was first raised in an 1842 case, which arose after a ship transporting poor Scottish and Irish emigrants to Philadelphia sunk. ${ }^{68}$ The Pennsylvania circuit court recognized the legality of killing and eating humans (after drawing lots) and sacrificing passengers if it were essential to the sailors' survival.

Biber argues that "'cannibalism' was wielded discursively to differentiate the colonial citizen from savagery, atavism, and abjection, all of the things that are outside law." ${ }^{69}$ Beyond the specific cases of maritime cannibalism, the real captives and victims of cannibalism were the colonized. As Biber observed:

Cannibal discourse also operated as a metaphor for consumption, where everything that is outside law's empire is colonised, incorporated into the body of law, regulated, controlled and classified. Rejecting all accusations of its own cruelty, the common law consumes the atavism of its Others. ${ }^{70}$

In the so-called post-colonial era, the law of self-consumption illustrates the broader phenomenon of a "jurisprudence of disgust," to use an expression that Alison Young developed to describe the legal censorship of provocative or "obscene" artwork. ${ }^{71}$ A significant dimension of contemporary law making can be characterized as a response to what is considered disgusting around or among us, which reflects an endeavor to confine and tame what repulses us. This is particularly obvious in the context of what legal scholar Kim Krawiec calls "taboo trades" (and economist Alvin Roth dubs "repugnant markets"); that is, the exchanges and transactions of products that are considered culturally immoral and uncaring, such as those involving organs, babies, sex, drugs, and corruption. ${ }^{72}$

Milk, placenta, and feces consumption can be sites of empowerment and relationality for individuals and groups; however, their growing popularity and the repugnance they elicit in some provides a pretext for the law to reach into bodies. In the eyes of the law, one of the problems with such practices is that they destabilize conventional forms of governance, calling for the mediation of state-sanctioned organizations into people's decisions about what to take in and out of their bodies. Depending on the context, milk, placenta, and feces are either seen as refuse to be discarded, or as precious substances to be donated or sold. Placenta and feces are viewed as waste products until a use can be found for them whereas milk is viewed as nourishment until there is no one to breastfeed. Milk, placenta, and feces are also regarded as wastes when contaminated by viruses, bacteria, parasites, or pollutants. From an anthropological perspective, bodily waste, inasmuch as it is associated with dirt, is, as Mary Douglas famously asserted, "matter out of place." 73 There is a spatial dimension to waste: it is what gets physically moved outside, often twice - outside the body and outside the place where it was first collected.

These three body products go through different regimes of value. They may be deemed as waste in one context, as having personal value when consumed and ritualized by their producers or their kin, or as having market value when exchanged.

\footnotetext{
${ }^{63}$ Biber, "Cannibals and Colonialism," 624; Mike Hayes, "Consuming Cannibalism."

${ }^{64}$ Biber, "Cannibals and Colonialism," 624.

${ }^{65}$ Biber, "Cannibals and Colonialism," 637.

${ }^{66}$ Simpson, Cannibalism and the Common Law.

${ }^{67}$ Simpson, Cannibalism and the Common Law.

${ }^{68}$ United States v. Holmes, 26 F. Cas. 360 (C.C.E.D. Pa. 1842).

${ }^{69}$ Biber, "Cannibals and Colonialism," 624.

${ }^{70}$ Biber, "Cannibals and Colonialism," 637.

${ }^{71}$ Young, "Aesthetic Vertigo."

${ }^{72}$ Krawiec, "Kidneys without Money"; Roth, "Repugnance as a Constraint on Markets."

${ }^{73}$ Douglas, Purity and Danger.
} 
Catherine Waldby and Robert Mitchell have shown that waste and value are dynamic processes. ${ }^{74}$ Once in the hands of established medical or commercial organizations, such as biobanks, hospitals, biotechnology companies and the like, milk, placenta, and feces acquire new medical and commercial value. The gold metaphor employed to talk about them when they are dispensed by medical entities is suggestive of this alchemic transformation: milk becomes "liquid" or "white gold," umbilical cord blood, "clinical gold," and fecal transplantation, "golden syrup." Categorizing milk, placenta, and feces as waste products may thus be problematic, as it delegitimizes their DIY and peer-to-peer uses, while vindicating taking and transforming them into expensive products or procedures.

\section{B-Eating Oneself Versus Eating Others}

Despite some exceptions and variations, legal systems generally appear to be more tolerant of the consumption of one's own body (i.e., autologous consumption) than the body of others (i.e., allogeneic consumption). In the U.S., the consumption of one's own placenta is currently unregulated by the federal government even if some states have begun to protect it as a matter of right. ${ }^{75}$ But the Food and Drug Administration (FDA) has consistently cracked down on attempts by businesses to manufacture and distribute pills containing ground-up placenta from multiple donors to consumers. ${ }^{76}$ Generally, the FDA is of the view:

\footnotetext{
... that autologous cells or tissues that are removed from an individual and implanted into the same individual without intervening processing steps beyond rinsing, cleansing, sizing, or shaping, raise no additional risks of contamination and communicable disease transmission beyond that typically associated with surgery. ${ }^{77}$
}

Thus, eating oneself fresh and unseasoned is subject to only minimal legal oversight. However, when it comes to eating others, the regulations tend to be modulated based on the degree of relation of the donor to the patient. Close relatives and kin are sometimes exempt from some of the requirements that fall upon unrelated donors. In the past few years, the FDA has announced that human cells, tissues, and cellular and tissue-based products collected from first-degree or second-degree blood relatives should be treated as less risky than those collected from other donors. ${ }^{78}$ In 2014 , the FDA proposed that a requirement be introduced that stool donors in particular had to be "known" to either the patient or the physician. ${ }^{79}$ The agency retreated in the face of opposition from patient advocates and medical professionals, but the suggestion is emblematic of the regulatory impulse by which autologous or in-group self-consumption is seen as deserving more deference than allogeneic or out-group selfconsumption. Similarly, in Neonatal Intensive Care Units the milk produced by an infant's parents tends to be treated more permissibly than donor milk collected from anonymous donors, such that hospitalized babies may be able in some hospitals to be bottle-fed fresh, unpasteurized colostrum or milk from their parents while donor milk must go through rigorous screening and processing before it is administered.

The policy rationales for the differentiated treatment of body materials collected from oneself, one's kin, or perfect strangers typically center upon issues related to safety, effectiveness, and cost. Autologous uses are viewed as safer than allogeneic uses given the lower risk of contracting communicable diseases from one's own's body materials or of being contaminated by bacteria, pollutants, or other potentially harmful components that one does not already have. In certain situations, particularly those related to transplants, autologous uses may be more effective given the reduced probability of experiencing rejection, an adverse immune response or of having to use immunosuppressive therapies. Finally, costs are optimized as screening, processing, storage, and shipping are minimized when one consumes one's own body. Another cost-saving aspect is that autologous uses reduce the need to establish and maintain formal programs or banks to solicit donations, find matches, screen donors, and process, store, and ship materials. ${ }^{80}$

The law places spouses, partners, close relatives, and household members under a favored regime based on justifications similar to those put forward to exempt autologous uses from heightened legal scrutiny, including, in the context of microbiome-based therapies, the idea that recipient and donor share a similar intestinal microbial constitution because of cohabitation or frequent interactions, common environmental exposures, or genetics. An added justification is that more flexible regulatory conditions

\footnotetext{
${ }^{74}$ Waldby, Tissue Economies, 84.

75 Cohen, "The Law of Placenta," 384-389.

${ }^{76}$ Cohen, "The Law of Placenta."

${ }^{77}$ Food and Drug Administration. "Same Surgical Procedure Exception," 3.

${ }^{78}$ Yano, "Four Food and Drug Administration Draft Guidance Documents," 1580-1581.

${ }^{79}$ Scheeler, "Where Stool is a Drug," 531-2.

${ }^{80}$ See, for example, Dexter v. Kirschner 984 F.2d 979, 983 (9th Cir. 1992), which upheld an Arizona Medicaid statute that did not cover allogenic bone marrow transplants but did cover autologous bone marrow transplants based (among other reasons) on the fact that it would have represented an additional expenditure for the state.
} 
may encourage gratuitous donations by known donors, an outcome deemed desirable based on the cultural uneasiness- or repugnance - related to bringing commerce into the realm of the body.

The legal regime governing individuals who consume themselves or their loved ones constitutes a form of state intervention into the self that rests on a view of the legal subject as a "pharmaceutical person," even if it is relatively permissive compared to completely allogenic uses. ${ }^{81}$ In her exploration of American reproduction, anthropologist Emily Martin showed how women represent themselves as fragmented, lacking a sense of autonomy in the world and feeling carried by forces beyond their control. ${ }^{82}$ Attempts at regulating milk, placenta, and feces consumption represent prime sites of fragmentation of the self. Participants who engage in self-consumption may be motivated by the desire to broaden themselves and expand their relations to others; however, as mentioned above, the law operates in the opposite direction, as it moves toward separation and segmentation. The law literally and figuratively breaks down people into products by subjecting them to rules, administrative demands, and/or market forces as embodied laborers. Martin analyzed how drugs are given life in U.S. culture; for example, Martin examined how pills have been made human with different personality traits. ${ }^{83}$ As bodily substances, such as milk, placenta, and feces, return in force into mainstream pharmacopeias, the converse dynamic can be observed. In medical and popular discourses, the body is now understood as a pharmaceutical one, which thus must be controlled and disciplined, especially when it is coded as female and reproductive. Tellingly, birth parents who seek to repossess their own placentas from medical facilities must often sign waiver releases, be instructed of the risks of contamination and handling associated with their own tissues, and sometimes even test negative for certain infections (if they have not been altogether prohibited from access). The pathologizing of body materials as soon as they are excised, expelled, or excreted from the body becomes a legal justification to restrain their human producer's autonomy.

At the same time, regulatory endeavors currently do not address the risks associated with exploitation and lack of access. Providers of milk, placenta, and feces could be exploited and marginalized populations' lack of access to high-quality healthcare could worsen if they are excluded from markets in bio-commodities. The argument is similar to that developed in the human body trade literature in general; that is, that a market in body products that is not regulated based on social justice principles tends to reproduce existing class, race, and gender hierarchies whereby underprivileged groups will sell their body materials to more affluent and powerful consumers due to a lack of meaningful choice and a lack of access to these commodities when they are needed.

\section{Conclusion}

Milk, placenta, and feces unsettle the boundaries between one body and the bodies of others and notions of value and waste, all the while re-establishing these very boundaries. They provide useful case studies for the broader phenomenon of self-eating or self-consumption, whereby humans consume their own bodily materials or other humans' bodily materials for ritual, nutritional, therapeutic, or other purposes. This renewed reliance on the human body as a source of meaning, nutrition, drugs, and therapy has been met with a revived formalism in the law. Much like during the golden age of European colonialism and medical cannibalism in the seventeenth and eighteenth centuries, the human body is today seen both as an object of care and a source of medicine. It is binary; it harbors both the potential to fall ill and contaminate and the potential to heal itself and others. There is a co-creation between self-consumption and the law in this context, as laws need to be enacted to transform "natural" substances, such as milk, placenta, and feces, into marketable products. Thus, the drive toward cell-based, microbiome-based, and other therapies based on body materials offers a new frontier for the law to reach deeper into legal subjects. A form of internal legal colonialism is at work, as individuals' own relationships to their bodies is mediated by legal institutions, but no efforts have been made to promote or require the redistribution of bodily resources necessary to achieve food and health justice for all.

\footnotetext{
${ }^{81}$ Martin, "The Pharmaceutical Person."

${ }^{82}$ Martin, The Woman in the Body.

${ }^{83}$ Martin, "The Pharmaceutical Person."
} 


\section{Bibliography}

\section{Primary Sources}

Dexter v. Kirschner 984 F.2d 979, 983 (9th Cir. 1992)

United States v. Holmes, 26 F. Cas. 360 (C.C.E.D. Pa. 1842)

\section{Secondary sources}

Ahuja, Niraj and Adrian J. Lloyd. "Self-Cannibalism: An Unusual Case of Self-Mutilation,” Australian and New Zealand Journal of Psychiatry 41, no 3 (2007): 294-295. https://doi.org/10.1080\%2F00048670601172814

American Academy of Pediatrics Section on Breastfeeding. "Breastfeeding and the Use of Human Milk." Pediatrics 129, no 3 (2012): e827-e841. https://doi.org/10.1542/peds.2011-3552

Argamany, Jacqueline R., Andrew Delgado and Kelly R. Reveles. "Clostridium Difficile Infection Health Disparities by Race Among Hospitalized Adults in the United States, 2001 to 2010.” BMC Infectious Diseases 16, no 454 (2016). https://doi.org/10.1186/s12879-016-1788-4

Asnicar, Francesco, Serena Manara, Moreno Zolfo, Duy Tin Truong, Mathhias Scholz, Federica Armanini, Pamela Ferretti, Valentina Gorfer, Anna Pedrotti, Adrian Tett, and Nicola Segata. "Studying Vertical Microbiome Transmission from Mothers to Infants by Strain-Level Metagenomic Profiling." Systems 2, no 1 (2017): e00164-16.

Bakken, Johan S., Thomas Borody, Lawrence J. Brandt, Joel V. Brill, Daniel C. Demarco, Marc Alaric Franzos, Colleen Kelly, Alexander Khoruts, Thomas Louie, Lawrence P. Martinellu, Thomas A. Moore, George Russell, and Christina Surawicz. "Treating Clostridium Difficile Infection with Fecal Microbiota Transplantation.” Clinical Gastroenterology and Hepatology 9, no 12 (2011): 1044-1049. https://doi.org/10.1016/j.cgh.2011.08.014

Biber, Katherine. "Cannibals and Colonialism." Sydney Law Review 27, no 4 (2005): 623-638.

Borody, Thomas J. and Alexander Khoruts. "Fecal Microbiota Transplantation and Emerging Applications." Nature Reviews Gastroenterology and Hepatology 9, no 2 (2011): 88-96. https://doi.org/10.1038/nrgastro.2011.244

Chong, Kay Ray. Cannibalism in China, Wakefield, NH: Longwood Academic, 1990.

Cohen, Mathilde. "Should Human Milk be Regulated?" UC Irvine Law Review 9 (2019): 557-634.

Cohen, Mathilde. "The Law of Placenta." Yale Journal of Law and Feminism 31, no 2 (2020): 337-409.

Cooper William C. and Nathan Sivin. "Man as a Medicine: Pharmacological and Ritual Aspects of Traditional Therapy Using Drugs Derived from the Human Body." In Chinese Science. Explorations of an Ancient Tradition, edited by Shigeru Nakayama and Nathan Sivi, 203-272. Cambridge: MIT Press, 1973.

Diamond, Cora. "Eating Meat and Eating People.” Philosophy 53, no 206 (1978): 465-479. https://doi.org/10.1017/S0031819100026334

Donley, Greer. "Regulation of Encapsulated Placenta," Tennessee Law Review 86 (2019): 225-287.

Douglas, Mary. Purity and Danger: An Analysis of the Concepts of Pollution and Taboo. London: Ark Paperbacks, 1966.

Eiseman, B., W. Silen, G.S. Bascom, and A.J. Kauvar, "Fecal Enemas an Adjunct in the Treatment of Pseudomembranous Enterocolitis." Surgery 44, no 5 (1958): 854-859.

Fildes, Valerie. Wet Nursing: A History from Antiquity to the Present. New York: Oxford, 1988.

Flanagan, Jack. "People are Attempting DIY Fecal Transplants without Medical Supervision and Putting Themselves at Risk of Deadly Infections, Warn Experts.” Daily Mail, February 18, 2018. http://www.dailymail.co.uk/health/article5400709/People-attempting-DIY-fecal-transplants.html

Fletcher, Ruth. "Reproductive Consumption.” Feminist Theory 7, no 1 (2006): 27-47.

Food and Drug Administration. "Same Surgical Procedure Exception Under § 1271.15(b): Questions and Answers Regarding the Scope of the Exception" (2017). https://www.fda.gov/media/89920/download

Fox, Alisa, Jessica Marino, Fatima Amanat, Florian Krammer, Jennifer Hahn-Holbrook, Susan Zolla-Pazner, and Rebecca L. Powell. "Evidence of a Significant Secretory-IgA-dominant SARS-CoV-2 Immune Response in Human Milk Following Recovery from Covid-19." MedRvix. May 8, 2020. https://doi.org/10.1101/2020.05.04.20089995

Frenken, Koen and Juliet Schor, "Putting the Sharing Economy into Perspective." Environmental Innovation and Societal Transitions 23 (2017): 3-10. https://doi.org/10.1016/j.eist.2017.01.003

Gélis, Jacques. History of Childbirth: Fertility, Pregnancy and Birth in Early Modern Europe. Boston: Northeastern University Press, 1996.

Germano, Sara. "Placenta-Products Maker MiMedx Draws FDA Attention; The Question: Are Its Products, Made From Placenta, 'Minimally Manipulated'?” Wall Street Journal, September 2013.

Giles, Fiona. “Two Breasts, Twelve Weeks.” In Please Touch. Body Boundaries, edited by Dana Ben-Dari, 91-121, New Jersey City: Mana Publication, 2018.

Gordon-Grube, Karen. "Anthropophagy in Post-Renaissance Europe: The Tradition of Medical Cannibalism." American Anthropologist 90, no 2 (1988): 405-409. https://doi.org/10.1525/aa.1988.90.2.02a00110 
Hayes, Emily Hart. "Consumption of the Placentain the Postpartum Period," Journal of Obstetric, Gynecologic \& Neonatal Nursing 45 (2016): 78-89. http://dx.doi.org/10.1016/j.jogn.2015.10.008

Hassiotou, Foteini, Adriana Beltran, Ellen Chetwynd, Alison M. Stuebe; Alecia-Jane Twigger, Philip Metzger Naomi Trengove, Ching Tat Lai, Luis Filgueira, Pilar Blancafort, and Peter E. Hartmann. "Breastmilk is a Novel Source of Stem Cells with Multilineage Differentiation Potential.” Stem Cells 30, no 10 (2012): 2164-2174.f https://doi.org/10.1002/stem.1188

Hayes, Mike. "Consuming Cannibalism. The Body in Australia's Pacific Archive." In Violence and the Body. Race, Gender, and the State, edited by Arturo J. Aldama, 151-170. Bloomington: Indiana University Press, 2003.

Heyes, Cressida. "Placenta-Eating and the Epistemology of Ignorance." Atlantis 37, no 2 (2016): 111-121.

Hinde, Katie and Zachery T. Lewis, "Mother's Littlest Helpers,” Science 348, no 6242 (2015): 1427-1428. doi: $10.1126 /$ science.aac7436

Hoffmann, Diane E. "Introduction. The Promise and Challenges of Microbiome-Based Therapies." Journal of Law, Medicine and Ethics 47, no 4 (2019): 476-481. https://doi.org/10.1177\%2F1073110519897725

Janszen, Karen. "Meat of Life." Science Digest 88 (1980): 78-122.

Jeffay, Nathan. "Israeli Firm Hopeful as it Starts Treating Covid-19 Patients with Placenta Cells," Times of Israel, April 16, $2020 \mathrm{https://www.timesofisrael.com/israeli-company-hopes-to-treat-coronavirus-patients-with-placenta-cells/}$

Jørgensen, Simon Mark Dahl, Christian Erikstrup, Khoa Manh Dinh, Lars Erik Lemming, Jens Frederik Dahlerup, and Christian Lodberg Hvas, "Recruitment of Feces Donors among Blood Donors: Results from an Observational Cohort Study." Gut Microbes 9, no 6 (2018): 540-550. https://doi.org/10.1080/19490976.2018.1458179

Krawiec, Kimberly. "Kidneys without Money.” Journal of Institutional and Theoretical Economics 175, no 1 (2019): 4-19. doi: 10.1628 / jite-2019-0003

Kristeva, Julia. Powers of Horror: An Essay on Abjection. New York: Columbia University Press, 1982.

Kroløkke, Charlotte. Global Fluids. The Cultural Politics of Reproductive Waste and Value. New York: Berghahn Books, 2018.

Kroløkke, Charlotte, Elizabeth Dickinson, and Karen A. Foss, “The Placenta Economy: From Trashed to Treasured BioProducts," European Journal of Women's Studies 25, no 2 (2018): 138-153. https://doi.org/10.1177\%2F1350506816679004

Laskaris, Julie. "Nursing Mothers in Greek and Roman Medicine.” American Journal of Archeology 112, no 3 (2008): 459464. doi: 10.3764/aja.112.3.459

Lee, Woo Jung, Lakshmi D. N. Lattimer, Sindu Stephen, and Marie K. Borum. "Fecal Microbiota Transplantation: A Review of Emerging Indications Beyond Relapsing Clostridium Difficile Toxin Colitis.” Gastroenterology \& Hepatology 11, no 1 (2015): 24-32.

Lindenbaum, Shirley. “Thinking about Cannibalism.” Annual Review of Anthropology 33, no 1 (2004): 475-498. https://doi.org/10.1146/annurev.anthro.33.070203.143758

Major, Michelle and Lee Ferran. "Fighting Cancer with Daughter's Breast Milk?” ABC News, May 27, 2009. https://abcnews.go.com/GMA/OnCall/story?id=7682702

Mao, Eric J., Colleen R. Kelly, and Jason T. Machan. "Racial Differences in Clostridium difficile Infection Rates are Attributable to Disparities in Health Care Access." Antimicrobial Agents and Chemotherapy 59, no 10 (2015): $6283-87$. doi: 10.1128/AAC.00795-15

Martin, Emily. The Woman in the Body: A Cultural Analysis of Reproduction. Boston: Beacon Press, 1987.

Martin, Emily. "The Pharmaceutical Person.” BioSocieties 1, no 3 (2006): 273-287. https://doi.org/10.1017/S1745855206003012

Palmquist, Aunchalee E. L. and Kirsten K. Doehler, "Contextualizing Online Human Milk Sharing: Structural Factors and Lactation Disparity Among Middle Income Women in the U.S.” Social Science and Medicine 122 (2014): $140-147$. https://doi.org/10.1016/j.socscimed.2014.10.036

Palmquist, Aunchalee E. L. and Kirsten K. Doehler. "Human Milk Sharing Practices in the U.S." Maternal Child and Nutrition 12, no 2 (2016): 278-90. https://doi.org/10.1111/mcn.12221

Park, Leslie, Anjali Mone, Jennifer C. Price, Demetrios Tzimas, Jacqueline Hirsh, Michael A. Poles, Lisa Malter, and Lea Ann Chena. "Perceptions of Fecal Microbiota Transplantation for Clostridium Difficile Infection: Factors that Predict Acceptance." Annals of Gastroenterology 30, no 1 (2017): 83-88. https://dx.doi.org/10.20524\%2Faog.2016.0098

Pipino, Caterina, Panicos Shangaris, Elisa Resca, Silvia Zia, Jan Deprest, Neil J. Sebire, Anna L. David, Pascale V. Guillot, and Paolo De Coppi. "Placenta as a Reservoir of Stem Cells: An Underutilized Resource?" British Medical Bulletin 105, no 1 (2013): 43-67. https://doi.org/10.1093/bmb/lds033

Rose, Nikolas. Powers of Freedom: Reframing Political Thought. Cambridge: Cambridge University Press, 1999.

Roth, Alvin E. "Repugnance as a Constraint on Markets," Journal of Economic Perspectives 21, no 3 (2007): 37-58. DOI:

10.1257/jep.21.3.37

Sachs, Rachel E. and Carolyn A. Edelstein. "Ensuring the Safe and Effective FDA Regulation of Fecal Microbiota

Transplantation," Journal of Law and the Biosciences 2, no 2 (2015): 396-415. doi: 10.1093/jlb/lsv032 
Santoro, Pablo. "Liminal Biopolitics: Towards a Political Anthropology of the Umbilical Cord and the Placenta." Body and Society 17, no 1 (2011): 73-93. https://doi.org/10.1177\%2F1357034X10394668

Scheeler, Alexandra. "Where Stool is a Drug: International Approaches to Regulating the use of Fecal Microbiota for Transplantation." Journal of Law, Medicine and Ethics 47, no 4 (2019): 524-540. https://doi.org/10.1177\%2F1073110519897729

Schor, Juliet B. and Connor J. Fitzmaurice. "Collaborating and Connecting: The Emergence of the Sharing Economy." In Handbook of Research on Sustainable Consumption, edited by Lucia A. Reisch and John Thøgersen, 410-425. Cheltenham, UK: Elgar, 2015.

Schutt, Bill. Cannibalism. A Perfectly Natural History. Chapel Hill: Algonquin Books of Chapel Hill, 2017.

Simpson, A.W. Brian. Cannibalism and the Common Law: A Victorian Yachting Tragedy. London: Hambledon Press, 1984.

Smith, Mark B., Colleen Kelly, and Eric J. Alm, "Policy: How to Regulate Faecal Transplants." Nature 506, no. 7488 (2014): 290-291. doi:10.1038/506290a

Sugg, Richard. “'Good Physic but Bad Food': Early Modern Attitudes to Medicinal Cannibalism and its Suppliers.” Social History of Medicine 19, no 2 (2006): 225-240. https://doi.org/10.1093/shm/hk1001

Taur, Ying, Katharine Coyte, Jonas Schluter, Elizabeth Robilotti, Cesar Figueroa, Mergim Gjonbalaj, and Eric R. Litmann, "Reconstitution of the Gut Microbiota of Antibiotic-Treated Patients by Autologous Fecal Microbiota Transplant." Science Translational Medicine 10, no 460 (2018): eaap9489. doi: 10.1126/scitranslmed.aap9489

von Staden, Heinrich. "Women and Dirt." Helios 19, nos 1 and 2 (1992): 7-30.

Waldby, Catherine and Robert Mitchell, Tissue Economies: Blood, Organs, and Cell Lines in Late Capitalism. Durham, NC: Duke University Press, 2006.

Wilson, Brooke C., Tommi Vatanen, Wayne S. Cutfield, and Justin M. O’Sullivan. “The Super-Donor Phenomenon in Fecal Microbiota Transplantation," Frontiers in Cellular and Infection Microbiology 9, no 2 (2019): 1-2. doi: 10.3389/fcimb.2019.00002

Yano, Kazuo, Alessondra T. Speidel and Masayuki Yamato, "Four Food and Drug Administration Draft Guidance Documents and the REGROW Act: A Litmus Test for Future Changes in Human Cell- and Tissue-Based Products Regulatory Policy in the United States?" Journal of Tissue Engineering and Regenerative Medicine 12, no 7 (2018): 1579-1593. https://doi.org/10.1002/term.2683

Young, Alison. "Aesthetic Vertigo and the Jurisprudence of Disgust" Law and Critique 11 (2000): 241-265. https://doi.org/10.1023/A:1008903818079

Young, Kenneth A. “Of Poops and Parasites: Unethical FDA Overregulation.” Food and Drug Law Journal 69, no 4 (2014): 555-574.

Yoshizawa, Rebecca S. "Review: Public Perspectives on the Utilization of Human Placentas in Scientific Research and Medicine," Placenta 34, no 1 (2013) 9-13. https://doi.org/10.1016/j.placenta.2012.10.014

Zhang, Faming, Wensheng Luo, Yan Shi, Zhining Fan, and Guozhong Ji. "Should We Standardize the 1,700-year-old Fecal Microbiota Transplantation?” American Journal of Gastroenterology 107, no 11 (2012): 1755. 